\title{
Effect of the Mat Pilates method on postural balance and thoracic hyperkyphosis among elderly women: a randomized controlled trial
}

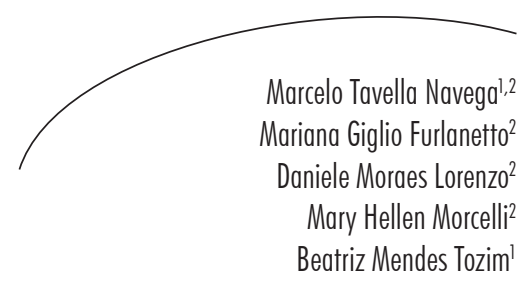

Abstract

Objective: To evaluate the influence of the Mat Pilates method on thoracic hyperkyphosis and postural balance among elderly women. Method: A randomized longitudinal study was performed involving 31 elderly women who were divided into two groups: the Control Group ( $n=17)$ and the Pilates Group $(n=14)$. The Pilates Group underwent training while the Control Group attended lectures. Evaluation consisted of specific balance (one-leg right and left) and thoracic kyphosis (computed biophotogrammetry) tests. The subjects were reassessed at the end of eight weeks. Data was analyzed by the Shapiro-Wilk test for normality, and the paired Student's t, the unpaired Student's t, the Wilcoxon, and the Mann-Whitney statistical tests, with a significance level of 5\% $(p<0.05)$. Results: The Pilates group maintained balance levels $(p>0.05)$ and had a mean thoracic kyphosis reduction of 6 degrees $(p<0.001)$. There was no significant difference $(p>0.005)$ in any of the variables in the Control Group. Conclusion: The present study found that the Mat Pilates method contributed to a reduction in thoracic kyphosis and the maintenance of balance in the elderly women investigated. REBEC: RBR-6jd8nq

Key words: Balance Postural; Kyphosis; Physical Therapy Modalities; Elderly.

Universidade Estadual Paulista Júlio de Mesquita Filho, Instituto de Biociências, Programa de Pósgraduação em Desenvolvimento Humano e Tecnologias. Rio Claro, São Paulo, Brasil.

2 Universidade Estadual Paulista Júlio de Mesquita Filho, Faculdade de Filosofia e Ciências, Departamento de Fisioterapia e Terapia Ocupacional. Marília, São Paulo, Brasil.

Study financing: Fundação de Amparo à Pesquisa do Estado de São Paulo (Research Support Foundation of the State of São Paulo) (FAPESP) for the granting of Scientific Initiation grants, process $n^{\circ} 11 / 12585-8$.

Correspondence

Beatriz Mendes Tozim

E-mail: beatriztozim@yahoo.com.br 


\section{INTRODUCTION}

The elderly suffer from a reduced balance capacity, which is caused by alterations in the relationship between sensory data acquisition and motor activity. ${ }^{1}$ The sensory and motor systems, in conjunction with the nervous system, comprise the framework for postural control ${ }^{2}$, whose functional purpose is to maintain postural balance and orientation. ${ }^{3}$

A loss of postural balance can be explained by a failure in the proper functioning of the Central Nervous System (CNS), which receives information from the visual, vestibular and somatosensory systems. The failure send this signal to the CNS causes a loss of balance. ${ }^{4}$

An additional aim of postural control is what is known as postural orientation, which consists of the interaction between the positioning of one's body and vision, gravity, support surfaces and internal references. ${ }^{3}$ Disorders in postural orientation are common among the elderly. ${ }^{5}$ One of these disorders is thoracic hyperkyphosis, which is defined as postural misalignment involving a pinching of the vertebra at the thoracic height of the sagittal plane, allowing the clinical observation of an increase in the thoracic curvature. ${ }^{6}$

Engaging in regular physical exercise is an important factor in the reduction of alterations in posture ${ }^{7}$ and balance ${ }^{8}$ caused by aging. ${ }^{7.8}$ Exercise imparts positive benefits with respect to the aging process, and studies have revealed the positive impacts of exercise on postural control.?

The Pilates Solo techniques represent a form of exercise that bolsters physical conditioning, postural alignment and improvements in motor coordination, ${ }^{10,11}$, which is why it is frequently prescribed by physical rehabilitation professionals and recommended for those that are thinking of beginning an exercise regimen. ${ }^{12}$

This method was created based on progressive exercises that involve stretching and strength training, ${ }^{13}$, and has the aim of offering a total body workout, while maintaining harmony between the body and the mind. ${ }^{10}$

The Mat Pilates training method focuses on the postural alignment of the spine and of the scapular and pelvic belt. ${ }^{14,15} \mathrm{It}$ is believed that both strength training and postural alignment help to improve thoracic hyperkyphosis.

Considering that thoracic hyperkyphosis can interfere with bodily oscillation, making static balance more difficult and increasing the probability of the elderly individual falling down, the search for initiatives that reduce these changes that arise from the aging process is extremely important.

As a result, this study aims to evaluate the impact of the Mat Pilates method on thoracic hyperkyphosis and balance among elderly women.

\section{METHODOLOGY}

Study environment and scope

A randomized, longitudinal study was conducted between the months of January and September, 2011. Experimental procedures were conducted at the Faculdade de Filosofia e Ciências of the Universidade Estadual Paulista Júlio de Mesquita Filho (the School of Philosophy and Science of the Júlio de Mesquita Filho Paulista State University - UNESP), at its campus located in Marília, São Paulo.

\section{Participants}

Participant recruiting began with the distribution of notifications regarding the study in locations that offered some form of assistance to elderly people. Thirty-one women, between the ages of 60 and 75, participated in the study. They were divided into two groups by means of a simple random selection process: the Pilates Group (PG) and the Control Group (CG). In terms of eligibility criteria, it was stipulated that the volunteers must be at least 60 years of age; have 
an angle of at least 40 degrees in the curvature of their spines at the thoracic height of the sagittal plane; be present for at least $75 \%$ of the training sessions and lectures; and not present neurological or motor sequelae, cognitive deficits, ${ }^{16}$ signs of nerve compression, ${ }^{17}$ ankylosing spondylitis, rheumatoid arthritis, vertebral tumors, vertebral fractures or cauda equina syndrome. ${ }^{18}$

\section{Experimental Procedures}

An initial evaluation, which was conducted for both groups, consisted of compiling a log for each participant containing their personal information, general data regarding their state of health, specific tests involving balance and measurements of angles of thoracic kyphosis. Upon conclusion of the initial evaluation, the PG group began training with the Mat Pilates method, while the CG group attended lectures. The training and the lectures lasted for eight weeks. At the end of the eight weeks, both groups were re-evaluated. The CG group, after re-evaluation, was submitted to eight weeks of Mat Pilates classes. The evaluations of the volunteer participants were performed by a certified physical therapist.

\section{Computerized bio-photogrammetry}

Computerized bio-photogrammetry is a method of measuring thoracic kyphosis. ${ }^{19}$ For this study, only angles of thoracic hyperkyphosis of 40 degrees or more were considered. ${ }^{20}$

The backs of the volunteers were exposed and cylindrical markers were placed over the spinous processes of the seventh cervical vertebra (C7) and the twelfth thoracic vertebra (T12). One at a time, the volunteers were positioned in an orthostatic position with their right side facing the wall and their left facing the camera. A 12 megapixel Fujifilm ${ }^{\circledR}$ camera was positioned at a distance of 2.8 meters from the volunteers at a height of 75 centimeters from the ground.

In order to measure the degree of thoracic kyphosis, AutoCad $2007^{\circledR}$ software was used, which made it possible to trace two lines running parallel to the $\mathrm{C} 7$ and T12 markers; the intersection of those lines formed the angle that denoted the degree of thoracic kyphosis. ${ }^{19}$

\section{Unipodal Test}

A unipodal test was conducted in which volunteers were asked to look straight ahead while standing one meter from the wall. Volunteers were then asked to raise one leg while keeping their eyes closed. The amount of time the volunteer was able to maintain the position was timed on a stopwatch. ${ }^{21}$ Three attempts were made with each leg with a time limit of 30 seconds. The attempt with the longest duration was recorded for each volunteer and used in the study. ${ }^{22}$ Each of the volunteers began the test by elevating their right leg.

\section{Mat Pilates Training}

The volunteers were trained in the Mat Pilates methodology over a period of eight weeks. They attended one hour sessions twice a week over a total of 16 sessions. Training groups were kept to a maximum of nine volunteers.

The Mat Pilates exercises implemented are shown in chart 1. Each exercise was undertaken progressively, evolving from beginner exercises through to advanced level exercises. In order to advance a level of difficulty, each volunteer had to conduct the exercises according to all of the principles set forth in the Mat Pilates method, which were taught at the beginning of the training period. The exercises were administered by two physical therapists with knowledge of the discipline of Mat Pilates. 
Chart 1. Mat Pilates methodology exercise program. Marília-SP, 2011.

\begin{tabular}{|c|c|c|}
\hline Purpose & Exercise & Duration \\
\hline $\begin{array}{l}\text { Strengthening of the hips and } \\
\text { stabilization of the torso }\end{array}$ & $\begin{array}{l}\text { Hundred level 1, } \\
\text { One leg stretch, } \\
\text { One leg circles }\end{array}$ & $\begin{array}{l}\text { Sets: } 5 \text { minutes } \mathrm{x} 2 \\
\text { Rest interval: two } \\
\text { minutes }\end{array}$ \\
\hline $\begin{array}{l}\text { Strengthening of the hips, stabilization } \\
\text { of the torso, stability and stretching of } \\
\text { the torso }\end{array}$ & $\begin{array}{l}\text { Hundred level 2, } \\
\text { One leg stretch, Saw } \\
\text { Neck, pull, Single leg lift }\end{array}$ & $\begin{array}{l}\text { Sets: } 4 \text { minutes x } 2 \\
\text { Rest interval: one minute }\end{array}$ \\
\hline $\begin{array}{l}\text { Strengthening of the hips, stabilization } \\
\text { of the torso, stability and stretching of } \\
\text { the hip and torso muscles }\end{array}$ & $\begin{array}{l}\text { Roll-up, Leg stretch, Scissors, Swan, Side } \\
\text { twist, Hundreds in standing, Table }\end{array}$ & $\begin{array}{l}\text { Sets: } 2 \text { minutes and } 30 \\
\text { seconds x } 2 \\
\text { Rest interval: one minute }\end{array}$ \\
\hline $\begin{array}{l}\text { Strengthening of the hips, stabilization } \\
\text { of the torso, stability and stretching of } \\
\text { the hip muscles }\end{array}$ & $\begin{array}{l}\text { Leg stretch while producing opposing } \\
\text { force, Breast stroke, Double leg stretch, } \\
\text { Spine stretch forward, Shell stretch, Standing } \\
\text { scissors, Standing star series, Standing } \\
\text { hamstring contraction and extension } \\
\text { series, Slices }\end{array}$ & $\begin{array}{l}\text { Sets: } 2 \text { minutes x } 2 \\
\text { Rest interval: one minute }\end{array}$ \\
\hline
\end{tabular}

\section{Lectures}

The control group attended four lectures in which the following subject matter was discussed in sequence: Changes due to the aging process and the act of falling down; changes due to aging and its effects on posture; physical activity, quality of life and overall health for the elderly. The lectures lasted approximately 45 minutes and were administered by the two physical therapists that administered the training sessions.

\section{Data analysis}

Exploratory statistical techniques were applied to analyze the data. After applying the ShapiroWilk test to verify the normality and homogeneity of the data, the paired Student's t test and the Wilcoxon test were applied to analyze the data in order to evaluate intra-group variables. The Mann-Whitney test was adopted for analysis of the inter-group variables. A significance level of $5 \%(p<0.05)$ was adopted to interpret the data.

\section{Ethical aspects}

The study was approved by the Research Ethics Committee of the School of Philosophy and Science of the Universidade Estadual Paulista Júlio de Mesquita Filho, case number 0341/2011. Each of the participants was briefed about the study and signed an Informed Consent Form, in accordance with Resolution No. 196/96 of the National Health Council.

\section{RESULTS}

Fifty-four elderly women were selected for the study, of which 15 were excluded for not having satisfied the stipulated selection criteria. As a result, thirty-nine participants were admitted to the present study. The elderly female participants were then randomly separated into two groups: CG $[\mathrm{n}=22 ; 65.4( \pm 4.03)$ years $]$ and PG $[\mathrm{n}=17$; $67.71( \pm 3.24)$ years]. Over the duration of the study, five volunteers decided to opt out of the CG group $(22.7 \%)$ and three from the PG group (17.6\%). As such, 31 elderly women, 17 in the CG group and 
14 in the PG group, participated in the entirety of the study. Table 1 shows the anthropometric characterization of the groups, which were homogenous with respect to age ( $p=0.097)$, height $(p=0.604)$, body mass $(p=0.328)$ and body mass index $(p=0.181)$.

Table 1. Characterization of the Pilates Group (PG) and the Control Group (CG) Marília-SP, 2011.

\begin{tabular}{lrccc}
\hline & \multicolumn{2}{c}{ PG $(\mathrm{n}=14)$} & \multicolumn{2}{c}{ CG $(\mathrm{n}=17)$} \\
\cline { 2 - 5 } & Mean & CI 95\% & Mean & CI 95\% \\
\hline Age (years) & 67.00 & $65.38-68.62$ & 64.88 & $62.80-66.96$ \\
Height (m) & 1.58 & $1.54-1.62$ & 1.60 & $1.55-1.64$ \\
Body mass $(\mathrm{Kg})$ & 76.66 & $69.83-83.47$ & 72.40 & $66.28-78.50$ \\
BMI $\left(\mathrm{Kg} / \mathrm{m}^{2}\right)$ & 30.68 & $27.82-33.54$ & 28.38 & $26.21-30.54$ \\
\hline
\end{tabular}

CI $95 \%=95 \%$ confidence interval; BMI $=$ body mass index.

The PG group participants were not present for $14.70 \%$ of the duration of the training period, whereas the CG group did not participate in $25.00 \%$ of the lecture series. The volunteers in the PG group were able to learn the principles of the method during the first week of training, in addition to finishing the simultaneous exercise program.

The results of the right unipodal support test did not reveal a significant difference between the evaluation and the re-evaluation phases in both the PG group ( $p=0.300$, test power of $62.08 \%$ ) and the CG group ( $p=0.653$, test power of $66.01 \%$ ). With respect to inter-group comparison, no difference was detected for the right unipodal support test regarding the evaluation ( $p=0.421$, test power of $57.10 \%)$ and the re-evaluation phases $(p=0.597$ test power of $50 \%$ ), as shown in table 2 .

The results of the left unipodal support test did not reveal a difference regarding intra-group analysis with respect to the PG group ( $p=0.109$, test power of $57.76 \%$ ) and the CG group ( $p=0.653$, test power of $50.37 \%$ ); the same is true for intergroup analysis during the evaluation ( $p=0.769$, test power of $53.00 \%$ ) and the re-evaluation phases, as shown in table 2 .

Table 2. Results of the right and left unipodal tests of the Pilates (PG) and Control (CG) Groups. Marília-SP, 2011.

\begin{tabular}{lccccc}
\hline & & \multicolumn{2}{c}{ RUT $(\mathrm{s})$} & \multicolumn{2}{c}{ LUT $(\mathrm{s})$} \\
\cline { 3 - 6 } & & Mean & CI 95\% & Mean & CI 95\% \\
\hline \multirow{2}{*}{ PG $(\mathrm{n}=14)$} & Evaluation & 4.44 & $3.53-6.31$ & 3.76 & $2.64-7.05$ \\
& Re-evaluation & 4.28 & $2.18-12.91$ & 5.27 & $3.70-7.78$ \\
\hline \multirow{2}{*}{ CG $(\mathrm{n}=17)$} & Evaluation & 4.85 & $4.06-7.63$ & 4.74 & $3.97-9.80$ \\
& Re-evaluation & 5.73 & $4.76-9.93$ & 4.05 & $4.34-8.95$ \\
\hline
\end{tabular}

RUT $=$ right unipodal test; $\mathrm{LUT}=$ left unipodal test; $(\mathrm{s})=$ seconds; $\mathrm{CI} 95 \%=95 \%$ confidence interval. 
The PG group showed a decrease in thoracic hyperkyphosis $(p<0.001$, test power of $71.12 \%$ ) after the training, whereas the thoracic hyperkyphosis levels of the CG group remained the same ( $p=0.303$, test power of $56.95 \%$ ). With respect to the inter-group analysis, no significant differences were detected between the groups regarding thoracic hyperkyphosis either during the evaluation period ( $p=0.554$, test power of $53.86 \%$ ) or the re-evaluation period ( $p=0.723$, test power of $51.00 \%$ ), as shown in table 3 .

Table 3. Thoracic hyperkyphosis results for the Pilates (PG) and Control (CG) groups. Marília-SP, 2011.

\begin{tabular}{llrlr}
\hline & \multicolumn{2}{c}{ Evaluation (in degrees) } & \multicolumn{2}{c}{ Re-evaluation (in degrees) } \\
\cline { 2 - 5 } & \multicolumn{2}{c}{ Mean } & CI 95\% & \multicolumn{2}{c}{ Mean } & CI 95\% \\
\hline PG $(\mathrm{n}=14)$ & 59.50 & $51.12-67.88$ & $53.43 *$ & $45.93-60.93$ \\
CG $(\mathrm{n}=17)$ & 56.76 & $51.72-61.81$ & 54.88 & $50.49-59.28$ \\
\hline
\end{tabular}

*Statistically significant intra-group difference $(p<0.05)$; CI 95\%= 95\% confidence interval.

\section{DISCUSSION}

The results of the present study indicate an improvement in thoracic hyperkyphosis and a maintenance of static balance after eight weeks of training with the Mat Pilates methodology.

One of the aims of the Mat Pilates method is to promote central stabilization and a strengthening of the body's core muscles (abdominal muscles, pelvic floor and the lumbar region) $)^{8,23}$ and the muscles of the scapular and pelvic belt. ${ }^{14}$

A study conducted by Cruz-Ferreira et al. ${ }^{15}$ evaluated the effect of the Mat Pilates method on the postural alignment of adult women, whose training in the discipline lasted six months. Results indicated a significant improvement in the sagittal alignment of the cervical and thoracic spine, corroborating the results of the present study, which indicated reductions in the degree of thoracic hyperkyphosis among study participants.

This reduction in thoracic hyperkyphosis through the application of the Mat Pilates methodology was also described as positive in elderly individuals that undertook 10 weeks of Mat Pilates classes; the results indicated improvements in thoracic hyperkyphosis when in an orthostatic position, as observed in five second video footage of each participant. ${ }^{24}$
The Mat Pilates method promotes the strengthening of the body's core muscles ${ }^{13,23}$ and of the muscles of the scapular and pelvic belt ${ }^{14}$, which govern the posterior stability of the torso, counteracting the force of gravity on the body and generating the resistance that makes it possible to maintain oneself in an orthostatic position. The method also improves dynamic stability among the elderly, ${ }^{6}$ in addition to improving the control and precision of upper and lower extremity movements. ${ }^{14}$

The individual aims to maintain his or her center of gravity within its limits of balance in order to maintain body stability, which is determined by postural control capability when there is no change in the support base. ${ }^{3}$ From that point, the Mat Pilates method results in improvements in balance ${ }^{13}$ and postural stability ${ }^{25}$ by executing a contraction of the postural and abdominal muscles. ${ }^{13}$

The mean of the stability values indicated a higher value for the PG group when the evaluations were compared. This difference, however, was not deemed statistically significant. Such an occurrence could be due to the small size of the sample, as reflected in the low degree of sample power. In addition, a review of the literature, undertaken by Francisco et al. ${ }^{26}$, which aimed to evaluate the efficacy of the Mat Pilates method among elderly individuals, concluded 
that this type of exercise program has proved to be highly efficacious at improving the static and dynamic balance of elderly women.

Studies ${ }^{27,28}$ have shown that the Mat Pilates method brings about static balance improvements among the elderly. The Romberg test was administered with the participants' eyes open, and the length and velocity of bodily oscillation were measured ${ }^{27}$. The force platform test was also conducted, in which participants alternated opening and closing their eyes, while also alternating standing on a stable and unstable (foam) surface for 30 seconds. ${ }^{28}$ These tests showed that the Mat Pilates method is effective at improving static balance. However, during this study, the unipodal support test did not return statistically significant results. Researchers concluded, therefore, that this may have occurred because the test was not sensitive enough to identify improvements in stability.

The Mat Pilates method, when practiced regularly, contributes to a reduction of thoracic hyperkyphosis and an improvement in balance when the postural, abdominal and paravertebral muscles are exercised, increasing stability and postural conscience as a result. ${ }^{10,25}$ In addition to promoting the strengthening and stretching of the body's muscular framework, Mat Pilates improves postural alignment ${ }^{11}$ and develops the motor coordination and balance of elderly individuals, reducing the risk of falling down. ${ }^{10}$

The present study was limited by the following factors: small sample size, the non-implementation of a dynamic stability evaluation, the nonimplementation of a post-training evaluation of the group and the non-implementation of a group that trained with conventional exercise techniques.

\section{CONCLUSIONS}

The data acquired during this study allowed researchers to conclude that the Mat Pilates method contributed to reductions in the degree of thoracic hyperkyphosis among elderly female study participants, as well as the maintenance of their balance.

\section{ACKNOWLEDGMENTS}

Researchers would like to thank the Fundação de Amparo à Pesquisa do Estado de São Paulo (the Research Support Foundation of the State of São Paulo - FAPESP)_for the financial support it provided for this study.

\section{REFERENCES}

1. Burke TN, Franca FJR, Meneses SRF, Cardoso VI, Pereira RMR, Danilevicius CF, et al. Postural control among elderly women with and without osteoporosis: is there a difference? São Paulo med j 2010;128(4):219-24

2. Duarte M, Freitas SMSF. Revision of posturography based on force plate for balance evaluation. Rev Bras Fisioter 2010;14(3):183-92.

3. Horak FB. Postural orientation and equilibrium: what do we need to know about neural control of balance to prevent falls? Age Ageing 2006;35(2): 7-11.

4. Kerber KA, Enrietto JA, Jacobson KM, Baloh RW. Disequilibrium in older people: a prospective study. Neurology 1998;51(2):574-80.
5. Rizzi PRS, Leal RM, Vendrusculo AP. Efeito da hidrocinesioterapia na força muscular e na flexibilidade em idosas sedentárias. Fisioter Mov 2010;23(4):535-43.

6. Regolin F, Carvalho GA. Relação entre cifose dorsal, densidade mineral óssea e controle postural em idosas. Rev Bras Fisioter 2010;14(6):464-69.

7. Bandeira FM, Delfino FC, Carvalho GA, Valduga R. Comparação entre a cifose torácica de idosos sedentários e praticantes de atividade física pelo método flexicurva. Rev Bras Cineantropom Desempenho Hum 2010;12(5):381-86.

8. Sá ACAM, Bachion MM, Menezes RL. Exercício físico para prevenção de quedas: ensaio clínico com idosos institucionalizados em Goiânia, Brasil. Ciênc Saúde Coletiva 2012;17(8):2117-27. 
9. Tse AC, Wong TW, Lee PH. Effect of low-intensity exercise on physical and cognitive health in older adults: a Systematic Review. Sports Med Open 2015;1(1):1-13.

10. Sacco ICN, Andrade MS, Souza OS, Nisiyama M, Cantuária AL, Maeda FYI, et al. Método pilates em revista: aspectos biomecânicos de movimentos específicos para reestruturação postural - Estudos de caso. Rev Bras Ciênc Mov 2005;13(4):65-78.

11. Ferreira C, Aidar F, Novaes G, Vianna J, Carneiro A, Menezes L. O método Pilates sobre a resistência muscular localizada em mulheres adultas. Motriz 2007;3(4):76-8.

12. Segal NA, Hein J, Basford JR. The effects of Pilates training on flexibility and body composition: an observational study. Arch Phys Med Rehabil 2004;85(12):1977-81.

13. Muscolino JE, Cipriani S. Pilates and the “powerhouse"-I. J Bodyw Mov Ther 2004;8(2):122-30.

14. Pata RW, Lord K, Lamb J. The effect of Pilates based exercise on mobility, postural stability, and balance in order to decrease fall risk in older adults. J Bodyw Mov Ther 2014;18(3):361-67.

15. Cruz-Ferreira A, Fernandes J, Kuo YL, Bernardo LM, Fernandes O, Laranjo L, et al. Does pilatesbased exercise improve postural alignment in adult women? Women Health 2013;53(6):597-611.

16. Tozim BM, Furlanetto MG, Lorenzo DM, Morcelli MH, Navega MT. Efeito do método Pilates na flexibilidade, qualidade de vida e nível de dor em idosos. ConScientiae Saúde 2014;13(4):563-70.

17. Ramírez CR, Lemus DMC. Disfunção da articulação sacro-ilíaca em jovens com dor lombar. Fisioter Mov 2010;23(3):419-28.

18. Ferreira MS, Navega MT. Efeitos de um programa de orientação para adultos com lombalgia. Act Ortop Bras 2010;18(3):127-31.
19. Rodrigues ACC, Romeiro CAP, Patrizzi LJ. Avaliação da cifose torácica de mulheres idosas portadoras de osteoporose por meio da biofotogrametria computadorizada. Rev Bras Fisioter 2009;13(3):205-09.

20. Kostuik JP. Adult Kyphosis: the adult spine-principles and practice. New York: Raven Press; 1991.

21. Freitas ERFS, Rogério FRPG, Yamacita CM, Vareschi ML, Silva RA. Prática habitual de atividade física afeta o equilíbrio de idosas? Fisioter Mov 2013; 26(4):813-21.

22. Hauser E, Martins VF, Teixeira AR, Zabaleta AD, Gonçalves AK. Relação entre força muscular e equilíbrio de idosos no programa de equilíbrio. ConScientiae Saúde 2013;12(4):580-7.

23. Willson JD, Dougherty CP, Ireland ML, Davis IM. Core stability and its relationship to lower extremity function and injury. J Am Acad Orthop Surg 2005;13(5):316-25.

24. Kuo YL, Tully EA, Galea MP. Sagittal spinal posture after pilates-based exercise in healthy older adults. Spine 2009;34(10):1046-51.

25. Emery K, Serres SJ, Mcmillan A, Côté JN. The effects of a Pilates training program on arm-trunk posture and movement. Clin Biomech 2012;25:124-30.

26. Francisco CO, Fagundes AA, Gorges B. Effects of Pilates method in elderly people: Systematic review of randomized controlled trials. J Bodyw Mov Ther 2015;19(3):500-8.

27. Hyun J, Hwangbo K, Lee CW. The effects of Pilates Mat Exercise on the balance ability of elderly females. J Phys Ther Sci 2014;26(2):291-93.

28. Bird ML, Hill KD, Fell JW. A Randomize controlled study investigating static and dynamic balance in older adults after training with pilates. Arch Phys Med Rehabil 2012;93(1):43-9. 